\title{
CARROS Y CABALLOS EN LA TRILOGÍA EURIPIDEA DE MICHAEL CACOYANNIS
}

\author{
Alejandro Valverde García \\ IES Santísima Trinidad (Baeza) \\ allenvalgar@hotmail.com
}

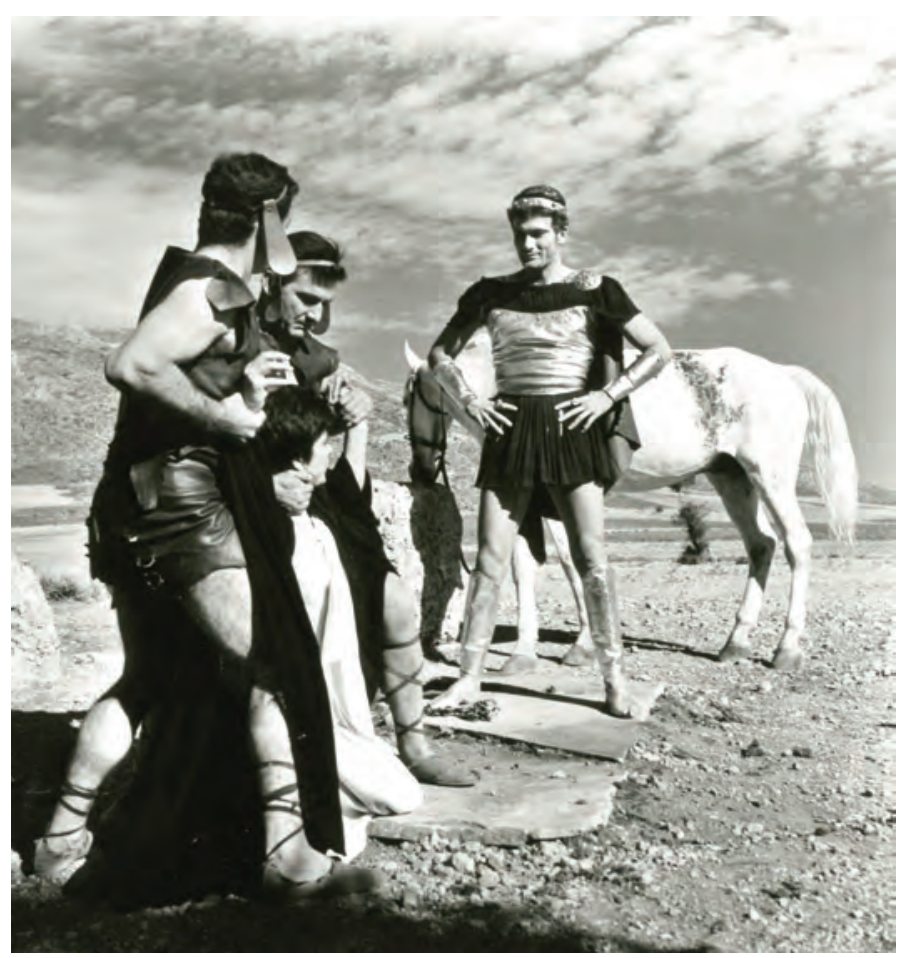

\section{RESUMEN}

En el presente artículo se analiza un elemento visual recurrente en las tres películas que el director grecochipriota Michael Cacoyannis filmó basándose en las tragedias de Eurípides Electra, Las troyanas e Ifigenia en Aulide. Los carros que transportan a las heroínas de estas tres obras y los caballos sobre los que cabalgan los villanos se transforman en un poderoso símbolo del destino inexorable reservado a las mujeres y de la soberbia y prepotencia de los hombres. Empleando este recurso puramente cinematográfico, que el director asocia frecuentemente a los cantos corales femeninos, se subraya con gran efectividad la denuncia contra los abusos de poder que subyace en los textos originales.

Palabras ClaVE: Michael Cacoyannis, Eurípides, cine, tragedia griega. 


\section{ABSTRACT}

«Chariots and horses at Michael Cacoyannis' Euripidean trilogy». In this article we analyse a recurrent visual element used at the Euripidean trilogy made by the Greek-Cypriot filmmaker Michael Cacoyannis based on the tragedies Electra, The Trojan Women and Iphigenia at Aulis. Chariots that carried women and horses rode by men become a powerful symbol of the women's inescapable fate and the men's pride and arrogance. By using this cinematographic resource, frequently associated by the director to women stasima, it's effectively emphasized the report against the abuse of authority hidden in the original texts.

KEY WORDS: Michael Cacoyannis, Euripides, cinema, Greek tragedy.

\section{INTRODUCCIÓN: ¿A CABALLO O EN CARRO?}

Afortunadamente, en los últimos años la filmografía sobre la trilogía trágica de Michael Cacoyannis se ha triplicado, señal de que este legado artístico sigue suscitando actualmente gran interés por su indiscutible relevancia para los estudios de la recepción de los textos clásicos en nuestra época moderna. A los primeros trabajos parciales de los profesores Marianne McDonald, Kenneth MacKinnon y Pantelis Michelakis se suman ahora dos tesis doctorales, las numerosas monografías de la profesora Anastasia Bakogianni y varios artículos publicados en revistas y libros colectivos de los que damos cuenta en las referencias bibliográficas finales.

Llegados a este punto podríamos pensar que ya está todo escrito sobre Electra, Las troyanas e Ifigenia, las tres películas que el director de origen chipriota realizó inspirándose en los inmortales versos de Eurípides. Ya sabemos que su encuentro con la antigua tragedia griega fue del todo casual, que el éxito internacional de la Antígona (1961) filmada por su amigo Yorgos Tsavelas le animó a acometer su propia relectura de la Electra, que compró un ejemplar de esta obra traducida al griego moderno pero por equivocación le dieron la de Eurípides y no la tradicional de Sófocles, que conoció a la actriz Irene Papas y que, teniéndola a ella en mente, escribió el guión de su película. Su brillante adaptación del texto clásico hizo que el propio Festival de Cannes se inventara una nueva categoría para premiar su trabajo, porque sin lugar a dudas con Electra Michael Cacoyannis había llegado a la cumbre de su carrera cinematográfica (Karalis, 2016: 86). Desde ese momento ya nunca abandonará las tragedias de Eurípides bien llevándolas a escena por todo el mundo o adaptándolas para el cine, como hace el año 1970 rodando en Atienza su versión de Las troyanas o en Grecia, tras la dictadura de los coroneles y el desastre de Chipre, con Ifigenia, dos ejemplos de deconstrucción del mito originario desde la perspectiva del naturalismo policromático (Karalis, 2016: 90).

Viendo estas tres películas como una unidad llama la atención la firme condena que subyace contra cualquier tipo de violencia, centrándose especialmente en el sufrimiento de las mujeres y de los niños en contraposición con el poder corrupto que sobre ellos ejercen los hombres (Bakogianni, 2015: 310). Es cierto que las heroínas trágicas de Eurípides siempre alzan la voz contra este tipo de opresión (McDonald Winkler, 2001: 75) pero también es verdad que en sus versos el autor no condena la guerra de una forma tan clara como cabría esperar según nuestra mentalidad moderna. 
La interpretación de las antiguas tragedias griegas como antibelicistas es más bien una relectura actual que nosotros hacemos (Bakogianni, 2017: 179) y que Cacoyannis se encarga de subrayar tanto con la adaptación del texto como con el uso magistral de la cámara, que, a modo de coro trágico, comenta la acción y lleva al espectador de la mano para que este se fije en detalles o expresiones de los actores que dan un nuevo sentido a los textos de Eurípides (Bakogianni, 2011: 186).

En este sentido, nuestro propósito es demostrar, a través de un análisis detallado de estos tres films, que Cacoyannis recurre a escenas inventadas usando caballos y carros para simbolizar esta oposición entre el abuso del poder de los caudillos griegos y el cruel destino que espera a las mujeres. Lógicamente, en los antiguos teatros griegos no había lugar para la incorporación de estos elementos dentro de la escena, como tampoco se mostraban ante el público los asesinatos y atrocidades que el mensajero se encargaba de explicar posteriormente. El director griego, sin embargo, haciendo uso de la libertad que le ofrece el lenguaje cinematográfico, se permite el lujo de reducir los diálogos y los cantos corales al mínimo a fin de que la imagen valga más que mil palabras, como nos demuestra con gran originalidad y maestría en los prólogos de las tres películas (De España, 2017: 119). Es verdad que, en la medida de lo posible, va a ser extremadamente fiel a los textos originales y que procurará no mostrar en pantalla las muertes de sus personajes, pero también es cierto que cargará las tintas en escenas de extrema violencia que no pertenecen a las obras de Eurípides. Con su inconfundible estilo, una singular combinación de elementos del cine más comercial de Hollywood con tintes del expresionismo alemán y del neorrealismo italiano, Cacoyannis presentará al espectador una recreación de los antiguos mitos bajo un falso realismo en el que tienen también cabida el lirismo, la estilización y el simbolismo (Bakogianni, 2017: 163). Así, desde la óptica del hiperrealismo simbólico (Karalis 2016: 65), los carros y caballos que vemos en la pantalla cobran un significado especial. Cada vez que la tragedia se avecina, las mujeres serán conducidas en carros hacia su fatídico destino, mientras que los hombres, mostrando su superioridad, las acosarán cabalgando sobre sus corceles, chillando, golpeando y humillando.

\section{CARROS DE DESHONRA Y DE LUJURIA}

Electra (1962) arranca con un impresionante prólogo mudo filmado al estilo de Eisenstein en el que vemos al rey Agamenón que regresa de la guerra de Troya ante la aclamación de su pueblo. Supuestamente hace su entrada triunfal no montado sobre su caballo sino transportado por un carro que lo conduce hacia un triste destino, aunque el director no ha querido revelárselo claramente al espectador. Sobre los altos muros de Micenas lo observa su truculenta esposa Clitemnestra que ha preparado ya el ritual de su asesinato con la ayuda de su amante Egisto. Toda esta escena que Cacoyannis se inventa antes de dar comienzo propiamente a los primeros versos de la tragedia de Eurípides tiene la misión de poner al público en antecedentes del drama pero al mismo tiempo va perfilando cada uno de los personajes mostrándonos sus gestos y reacciones a través de planos medios, primeros planos y planos en detalle. De este modo vemos al gran caudillo despojarse de sus armas ofensivas para 
ofrecérselas a sus queridos hijos, Electra y Orestes, mientras la mano de Clitemnestra lo arrastra hacia el interior del frío palacio. A continuación, ya en el ámbito privado, la cámara se detiene en su casco y su coraza depositados a los pies del baño que le ha preparado su mujer. Este proceso breve de vaciamiento coloca al héroe, desnudo e indefenso, en clara desventaja frente a sus asesinos, de forma que resulta innecesario representar en escena su muerte, sugerida ya desde el primer momento. Nos basta con contemplar los ojos de su hija, sus movimientos y su abatimiento final para entender cuál ha sido su final.

Para recalcar la humillación a la que Clitemnestra y Egisto someten a la princesa Electra el director introduce un nuevo carro que será el encargado de transportarla hacia su nuevo hogar, una destartalada choza en las afueras de la ciudad. Su futuro marido, un sencillo labrador de Micenas, acude al palacio para los esponsales y, al llegar, observa con sorpresa que en vez de esperarle una novia vestida de blanco los reyes le entregan a una mujer de luto, con la cabeza rasurada y un manto negro, señales inconfundibles del duelo que la joven lleva en su interior por la muerte de su padre y por su propia muerte en vida.

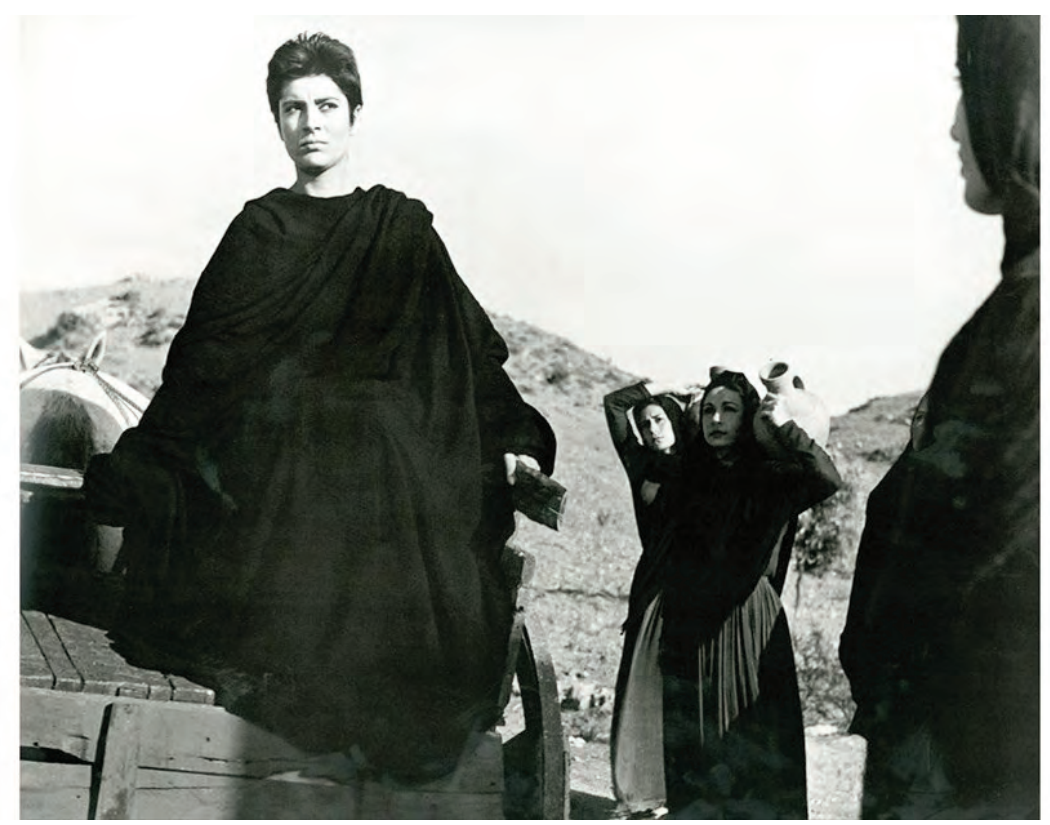

Los campesinos, desde la distancia, despiden con pañuelos a los nuevos esposos mientras estos se ponen de camino y entonan un himno triunfal inspirado en el segundo canto coral de la obra de Eurípides (vv. 726-736), en el que, con veladas alusiones políticas, se alude a otro famoso viaje, el de Apolo sobre su carro dorado (Chiasson, 2013: 209). Al igual que el dios restablece el orden de los elementos naturales así Electra podrá un día bailar, cantar y sonreír porque también a ella se le habrá hecho justicia. Sin embargo, este momento de solidaridad y de optimismo queda rápidamente ensombrecido por la irrupción de los guardias reales que, montados alti- 
vamente sobre sus caballos, arremeten con toda violencia contra el pueblo sofocando de inmediato sus muestras de cariño hacia la hija del rey (Valverde, 2012: 160). En la intimidad, fuera del alcance de los oídos de sus enemigos, será su esposo, el labrador, el que continúe la canción hasta el final, simbolizando que, a pesar de los abusos de poder, el hombre tiene también la capacidad de hacer el bien en grado heroico, como pronto demostrará él mismo respetando su virginidad y apoyándola en todo momento.

El carro conduce a la pareja por parajes inhóspitos a través de un sendero pedregoso hasta detenerse delante de una pobre cabaña blanca en torno a la que van apareciendo unas mujeres vestidas de negro que constituirán el coro de la tragedia y que no se apartarán ya de la protagonista, arropándola, animándola y comentando sus desdichas. Ellas son las que, a petición de Electra, le muestran el camino hacia la tumba del rey Agamenón, en una nueva escena inventada por Cacoyannis que por un lado viene a llenar el vacío dejado por la supresión de los cantos corales originales y, por otro, sirve para poner de relieve la oposición entre la entereza y fidelidad de la heroína y la villanía de Egisto, el asesino de su padre. Para lograr su propósito el director hace que en el momento de mayor intensidad emotiva, cuando la joven hace sus ofrendas y dirige a su padre dulces palabras, aparezca repentinamente el rey usurpador montado a caballo y acompañado de algunos de los guardias del palacio (Bakogianni, 2017: 173). Nuevamente aquí los hombres, abusando de su situación privilegiada y de su fuerza bruta, atemorizan a las mujeres, las acosan rodeándolas con los caballos y, finalmente, descargan sobre Electra su ira, maniatándola para que Egisto la pueda abofetear con toda impunidad y termine pisoteando con desprecio las flores depositadas sobre la lápida de Agamenón. Cacoyannis transmite así al espectador una imagen mucho más positiva de la heroína por oposición al personaje del villano, representando un acto de extrema impiedad y cobardía (Bakogianni, 2011: 179).

El último carro que vemos en esta película es el que transporta a la altiva Clitemnestra hacia la casa del labrador. En esta escena, cargada de simbolismos y rodada bajo un cielo que se va cubriendo y ensombreciendo por momentos (Moschovakis, 1995: 32), hallamos el clímax trágico con el enfrentamiento verbal de la reina y de su hija. Este nuevo carro no es un pobre carromato destinado a la carga de animales, de aperos de labranza o de sacos de grano. Es el vehículo oficial empleado por la reina para sus encuentros furtivos y adúlteros con su amante ya antes del asesinato de Agamenón. Es un símbolo claro de la soberbia, del poder despótico, del uso desmedido de las riquezas y de los amores ilícitos de esta madre fálica que, en cierto sentido, ha sido capaz de castrar psicológicamente a sus propios hijos (Karalis, 2016: 89). Sobre él aparece pavoneándose Clitemnestra delante de Electra y del resto de campesinas (Chiasson, 2013: 212), acompañada por tres esclavas troyanas que siempre lleva consigo como justa compensación por el sacrificio de su hija primogénita, Ifigenia (Bakogianni, 2011: 186). Electra le presta su mano, poniéndose a la altura de las propias esclavas, para hacerle ver a su madre las penalidades y la humillación que tiene que soportar desde el día en que la casó con el labrador. Tras las duras palabras que ambas se intercambian tendrá lugar el último asesinato con el que Electra y Orestes piensan restablecer el orden moral sobre Micenas. 


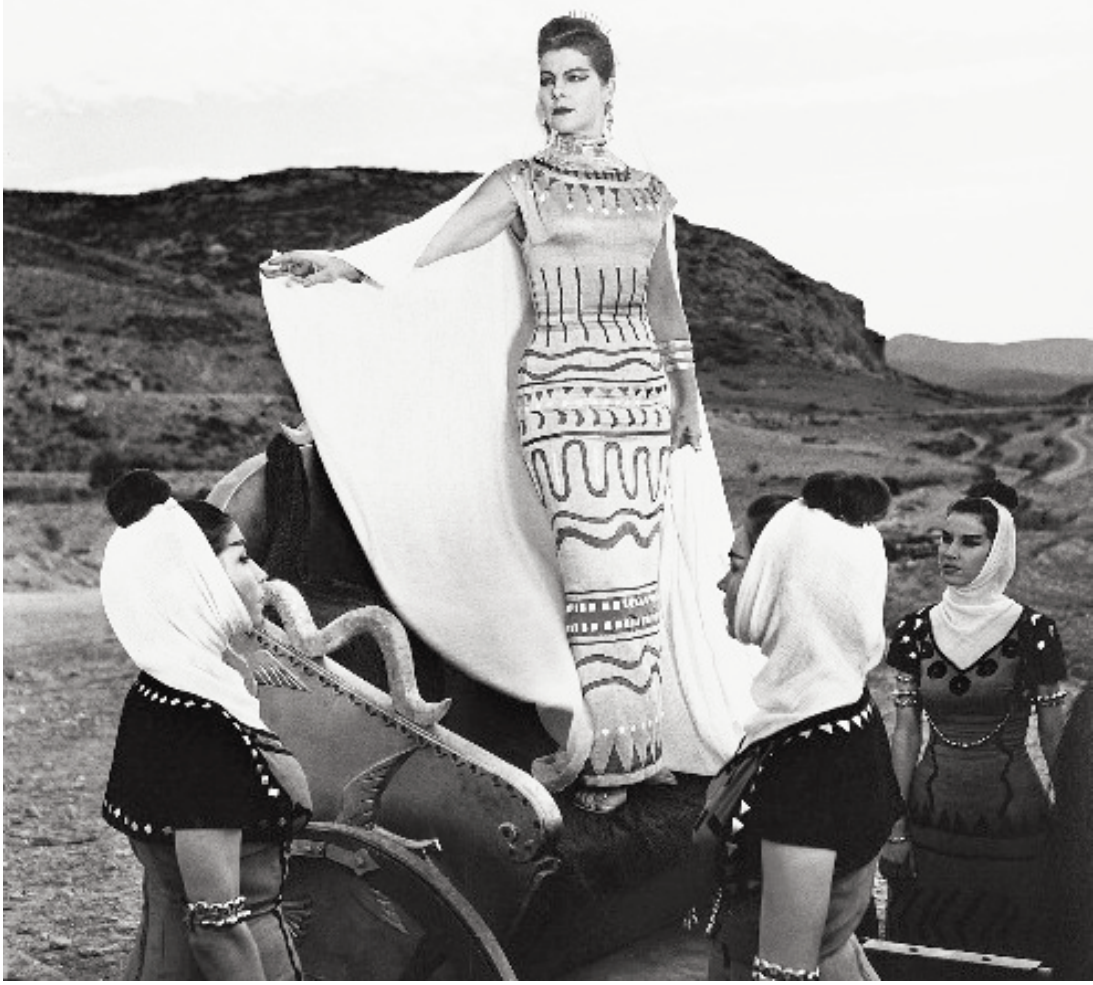

La reina entra lentamente dentro de la choza donde le espera una muerte segura de manos de sus propios hijos. Tampoco aquí Cacoyannis representa su final de forma abierta, pero la reacción de las mujeres del coro frente a la impasibilidad de las esclavas troyanas o la carrera desbocada de los caballos que tiran atropelladamente del carro de la reina son signos inconfundibles de que la venganza al fin se ha consumado (Mitiloudis, 2011: 76). A los gritos de las campesinas acude todo el pueblo, que se agolpa frente a la puerta de la casa esperando la confirmación de sus sospechas. Electra y Orestes, arrepentidos por el crimen cometido, emprenderán el camino hacia el exilio consumidos por el dolor de los remordimientos. No encuentran consuelo ni apoyo para este último viaje, que tendrán que realizar no a caballo ni sobre un carro sino a pie, tocando la misma tierra que sigue pidiendo venganza por la sangre derramada.

\section{CARAVANA HACIA LA ESCLAVITUD}

En la línea de su anterior película trágica, Las troyanas (1971) añade al aparente realismo con el que se muestra la narración fílmica un mayor grado de auste- 
ridad, tanto en vestuario como en música y decorados, creando una atmósfera de cierto ascetismo (Valverde, 2015: 336). Las imágenes de violencia contra las mujeres y los niños que Cacoyannis introduce ahora son todavía de una crueldad mayor, como podemos comprobar ya desde el arranque del film, con un prólogo inventado en el que el director no solo renuncia a poner en escena a los dioses sino que deja claro, mediante una voz en off, que la responsabilidad de la guerra de Troya es solo de los hombres (García Romero, 1998: 201). En estos primeros minutos del largometraje se nos muestra, en imagen congelada, cómo los griegos meten a empujones en carros a las mujeres y las separan de sus hijos pequeños. Las tratan con gran violencia, conduciéndolas a golpes como si fueran animales (Bakogianni, 2015: 295). Paralelamente observamos a los caudillos griegos montados sobre sus caballos y llevándose a sus barcos el botín obtenido. A continuación vemos fugazmente cómo un carro conduce también a la bella Helena, a la que los soldados tratan de forma muy diferente al resto de las mujeres, quizás por temor o por respeto (Willis, 2005: 125). A través de unas breves escenas al público le ha quedado claro que la mujer de Menelao les ha servido de excusa perfecta a los aqueos para destruir la ciudad enemiga y para hacerse con su oro.

El hilo conductor que servirá de enlace entre los diferentes episodios que dan cuerpo a esta tragedia será el personaje del heraldo de los griegos, Taltibio, con sus idas y venidas al campamento donde tienen recluidas a las esclavas troyanas. Sus apariciones en escena, siempre galopando sobre su caballo, traerán a las mujeres noticias cada vez más dolorosas, empezando por el cruel destino que le espera a Casandra y siguiendo con la orden de que Astianacte debe ser arrojado desde lo alto de las murallas de la ciudad.

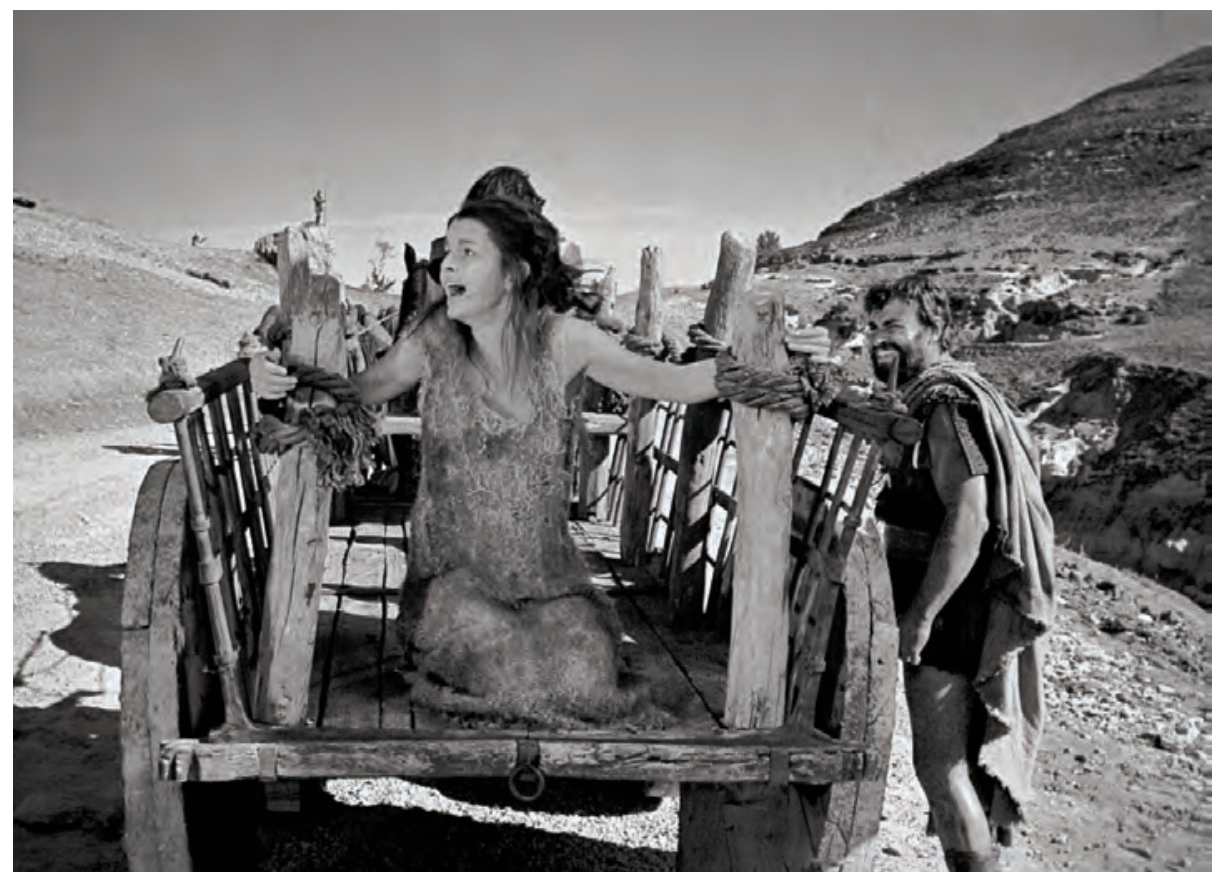


La secuencia del traslado de la profetisa Casandra, hija de la reina Hécuba, hasta las naves aqueas para servir de esclava en el lecho del rey Agamenón está filmada de forma muy impactante, utilizando recursos fílmicos como el zoom en staccato, el giro de 180 grados o la cámara subjetiva, que no hacen sino transmitir al espectador la extrema desolación que la princesa está sufriendo en esos momentos (Valverde, 2015: 338). Cubierta de harapos hechos jirones, de los que trata de librarse como si fueran serpientes venenosas, Casandra es subida por Taltibio a la fuerza a un carro destartalado, vehículo a todas luces indigno para un miembro de la familia real. Ella, que se había consagrado al dios Apolo, no da crédito a lo que los griegos piensan hacer con su vida, por eso, en medio de alucinaciones y premoniciones, entre espasmos y convulsiones, chilla y se agarra a las maderas del carro en un último intento de mostrar su desesperación, hasta que finalmente se desvanece y, con el giro de la cámara (Willis, 2005: 132), ya solo ve el camino polvoriento que queda tras de sí y un mundo al revés, recurso que ya había empleado Cacoyannis en la escena de la tumba de Agamenón en Electra, cuando la protagonista ha sido vejada y emite un grito desgarrador de impotencia. De este modo, el público ve en pantalla lo que las propias víctimas están observando, estableciéndose un fuerte lazo de empatía con los personajes femeninos (De Martino, 2009: 380).

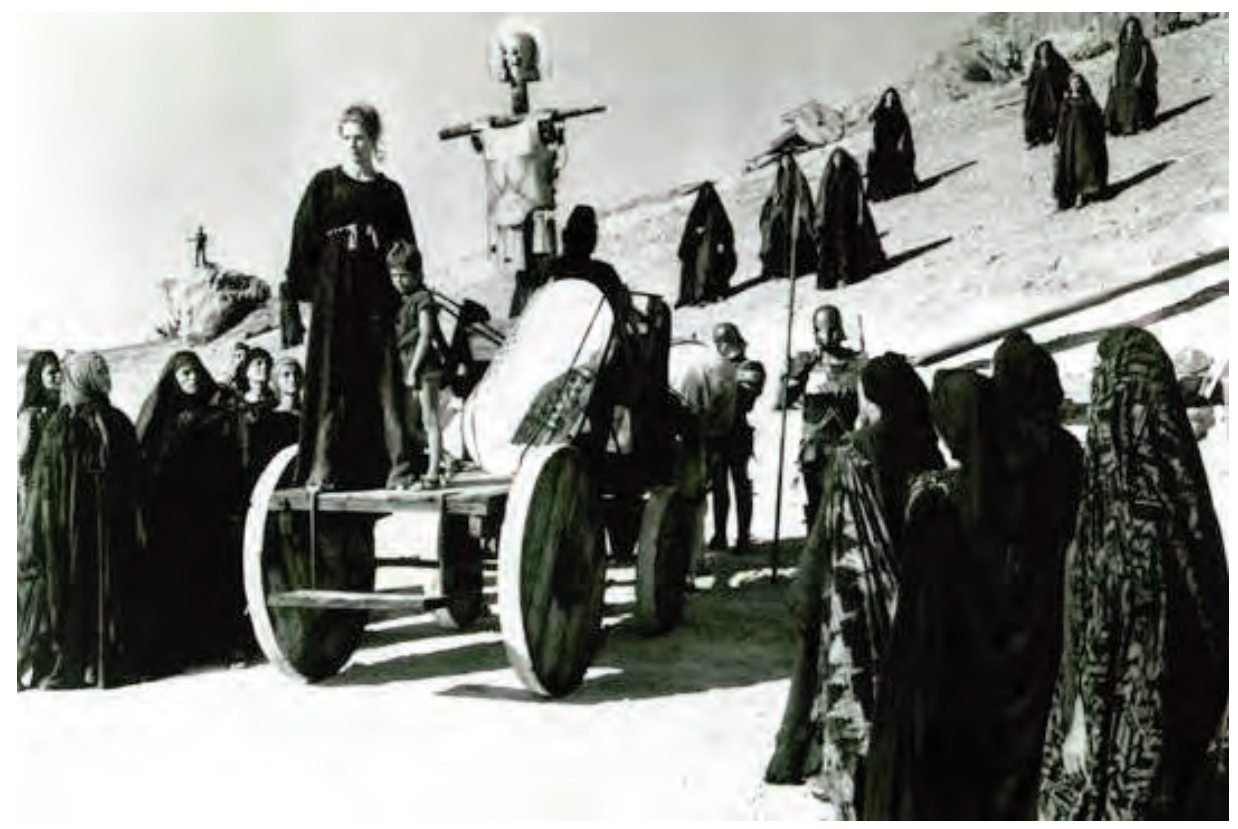

También Andrómaca, la viuda del gran Héctor, es conducida con su pequeño hijo Astianacte hasta el grupo de troyanas después de haber visto degollada a su cuñada Políxena a los pies de la tumba de Aquiles, inmolada por los griegos como ofrenda a los dioses. En este caso el carro que los transporta es muy estilizado y contiene las armas del esposo muerto en combate, lo cual es una prueba evidente de que madre e hijo son considerados también parte de ese mismo botín. Cuando 
Taltibio aparezca nuevamente para comunicarle que los griegos han decidido la muerte de su hijo también ella lanzará un grito ensordecedor, se echará polvo en la cabeza y correrá para intentar salvar a su pequeño (Bakogianni, 2017: 167), pero cuando comprende que nadie vendrá a socorrerla y ve que un soldado se lleva a Astianacte hacia lo alto de la ciudad, bajo un estado de shock vuelve a subir lentamente al carro sin resistirse, arrastrando con torpeza sus pies como una muerta viviente.

Las troyanas es, de las tres películas que constituyen la trilogía euripidea de Cacoyannis, la que más cantidad de carros pone en escena. Grupos numerosos de mujeres son conducidas a los barcos en repetidas ocasiones, mientras que los soldados se encargan de descargar violentos golpes sobre ellas para que no se resistan a su inevitable destino. Así ocurre en la escena en la que los jinetes griegos acuden a sofocar la revuelta de un grupo de troyanas que quieren apedrear a Helena al ver cómo esta se baña con el agua que a ellas, muertas de sed, se les niega, una nueva adición del director (Valverde, 2015: 336) que ayuda a comprender mejor la angustia de estas mujeres y el odio que sienten hacia la desvergonzada esposa del rey Menelao (McDonald, 1983: 244). En este sentido, se puede afirmar que Cacoyannis se aprovecha de los recursos cinematográficos que tiene a su alcance para aumentar la tensión y el efecto catártico de la antigua tragedia griega, en la que jamás se mostraba abiertamente la violencia ante el público (Bakogianni, 2017: 174). Por otra parte, la forma de representar el personaje de Helena, desnuda tras las tablas de la choza donde está recluida, con un primer plano de sus ojos seductores y luego ataviada como una verdadera reina en contraste con las pobres troyanas y con la propia reina Hécuba pone de manifiesto su potencial erótico y su superioridad sobre el resto de los personajes (Winkler, 2017: 357). Curiosamente a ella no le espera ningún carro que la lleve hasta las naves aqueas sino que son los propios soldados los que le abren paso entre la multitud de esclavas y los que la conducen hasta el barco de Menelao.

En la parte final del film vemos a Taltibio que reaparece sobre su caballo para impedir el suicidio de la reina Hécuba y para asegurarse de que el último grupo de troyanas suba a sus respectivos barcos. En esta escena, como ocurría en Electra, las mujeres asumen su trágico destino y solemnemente avanzan por su propio pie perdiéndose entre la oscuridad de la noche y los restos humeantes de la ciudad.

\section{CARROS DE FIESTA Y DE LUTO}

En su última adaptación de los versos de Eurípides Michael Cacoyannis nos conduce hasta el origen del drama de la familia de Agamenón. Si en Electra asistíamos a su asesinato a la vuelta de la guerra de Troya y en Las troyanas comprobábamos el cruel castigo infligido a las mujeres de los vencidos ahora comprenderemos de dónde arranca tanta maldad y tanto deseo de venganza.

$\mathrm{Al}$ igual que los antiguos tragediógrafos griegos fueron reduciendo las intervenciones corales en beneficio de las partes dialogadas de los actores, en Ifigenia Cacoyannis reduce sensiblemente el papel del coro de las compañeras de la protagonista centrando su atención en la masa incontrolable del ejército aqueo, que estará omnipresente como elemento amenazador (McDonald, 1983: 144). Así, con una amplia 
panorámica de las naves varadas en la playa y de los soldados consumidos por el tedio y la inactividad sustituye la descripción lírica de los versos 164-302 de la párodo de Ifigenia en Áulide (García Romero, 1998: 197). De igual forma el estásimo tercero (vv. 1036-1097) del texto original se verá reemplazado por los comentarios de las amigas de Ifigenia, mientras que el director inventará nuevos temas musicales para intensificar los momentos más emotivos, como ocurre con las dulces canciones que Clitemnestra entona para su hija mientras la acaricia o la abraza.

En el prólogo de este tercer film Cacoyannis presenta a Agamenón y a Menelao realizando una entrada solemne sobre sus caballos frente a la tropa que les hace pasillo a uno y otro lado (Bakogianni, 2015: 302). Ante el evidente descontento de las huestes el rey los anima a participar en una sangrienta cacería. De ese modo, un grupo de jinetes mata a flechazos los rebaños del colegio sacerdotal cometiendo la impiedad de acabar también con el ciervo sagrado que custodia el adivino Calcante. A través de los ojos del animal (como más adelante ocurrirá en la escena de la caza y captura de la inocente Ifigenia) el director nos permitirá ponernos nuevamente en el lugar de las propias víctimas del drama.

Si en Las troyanas era donde veíamos una mayor cantidad de carros, en Ifigenia, donde predomina el elemento masculino, serán los caballos los que estén en un primer plano, padeciendo la desidia y el calor de unos días interminables en los que no sopla el viento, conduciendo a los soldados en sus estériles escaramuzas y, sobre todo, portando al insidioso Odiseo, a quien también Cacoyannis da un papel mucho más relevante que en la tragedia de Eurípides.

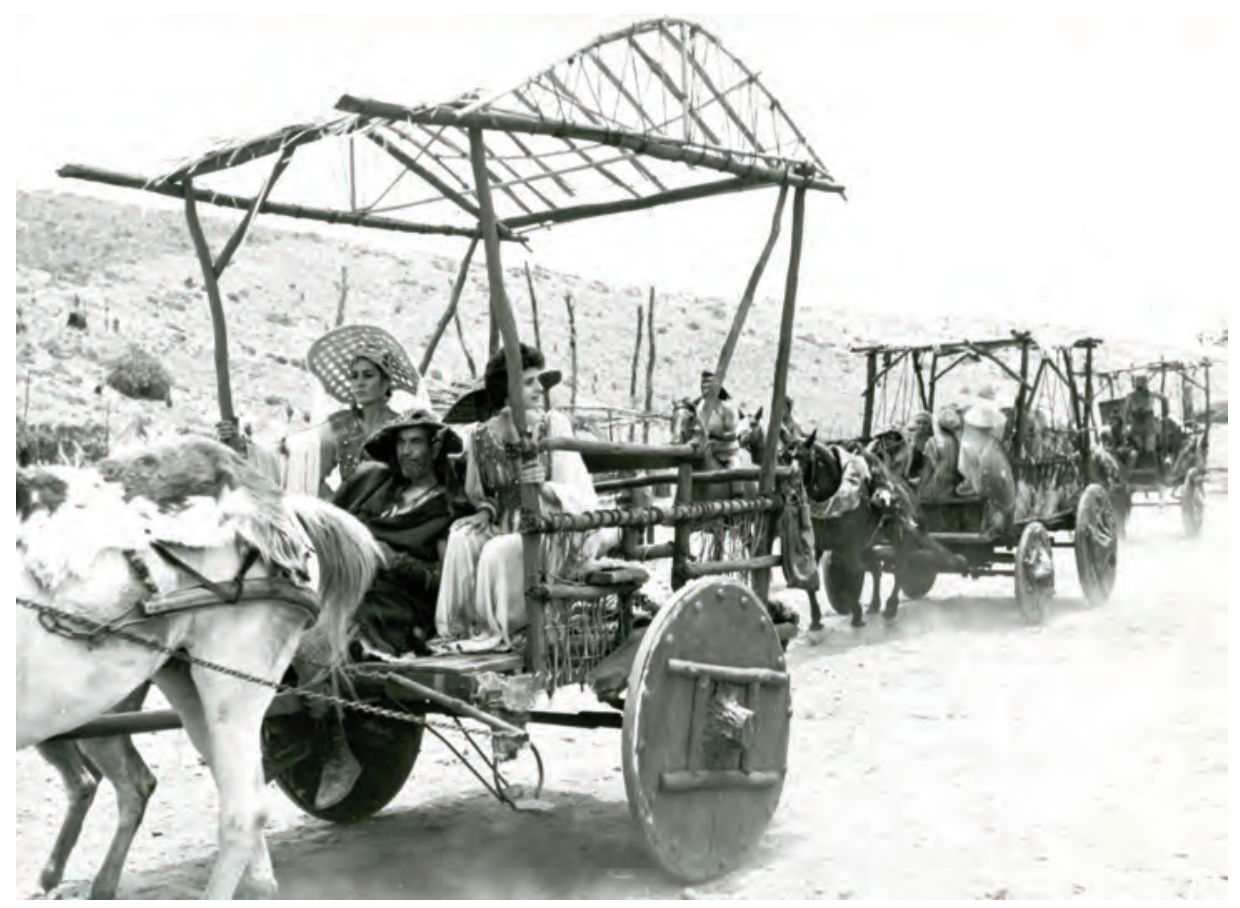


En cuanto al recurso de los carros, en esta ocasión el director nos muestra una caravana que parte feliz de Micenas rumbo a Áulide cuando Clitemnestra recibe la falsa noticia de que su esposo Agamenón prepara en el campamento los esponsales de su hija primogénita, Ifigenia, con el valeroso Aquiles. Durante el camino, las compañeras de la joven van entonando un canto que evoca el amor y la primavera, mientras que esta sigue emocionada y a la vez inquieta ante la boda inminente. Pero estas tres carretas en el fondo vuelven a ser un símbolo del fatídico destino cuando se revelan las verdaderas intenciones del padre de la novia. En vez de boda habrá un cruento sacrificio. Ifigenia intentará escapar de la muerte pero entiende que, por encima de Agamenón, tiene mucho más poder la masa de soldados, manipulados por Odiseo y por Calcante, por lo que, finalmente, decide entregarse de forma voluntaria.

Esta tercera tragedia no termina, como veíamos en las dos películas anteriores, con la salida de los personajes hacia un destino incierto. Una vez que el sacrificio se ha consumado y con los vientos ya favorables, la tropa corre hacia los barcos ante la atenta mirada de Clitemnestra, la cual, subida al carro que la conducirá de vuelta a casa, piensa solamente en vengar este crimen cuando su esposo regrese de la guerra de Troya (García Romero, 1998: 200). Con el plano congelado del rostro de la reina que transmite al espectador una mezcla de odio e impotencia, Cacoyannis cierra una trilogía que había empezado con la imagen de Clitemnestra esperando ansiosa la llegada de su marido. Adaptando de forma admirable los versos de Eurípides y siendo fiel al espíritu del antiguo drama ático el director logra transmitirnos su propia relectura actualizada. $Y$ al final el mensaje que permanece es su valiente y firme condena hacia cualquier tipo de violencia.

\section{REFERENCIAS BIBLIOGRÁFICAS}

Bakogianni, A. (2009): «Voices of resistance: Michael Cacoyannis’ The Trojan Women (1971)», BICS 52: 45-68.

- (2011): Electra Ancient and Modern: Aspects of the Reception of the Tragic Heroine, Institute of Classical Studies, London.

— (2015): «The anti-war spectacle: Denouncing war in Michael Cacoyannis' Euripidean Trilogy», en Bakogianni, A. - Hope, V. M. (eds.), War as Spectacle: Ancient and Modern Perspectives on the Display of Armed Conflict, Bloomsbury, London, pp. 291-311.

_ (2017): «Hollywood Meets Art-House Cinema: Michael Cacoyannis' "Hybrid” Euripidean Trilogy», en Pomeroy, A. (ed.), A Companion to Ancient Greece and Rome on Screen, John Wiley \& Sons, Malden, pp. 163-185.

CHIAsson, C. (2013): «Re-politicizing Euripides: the power of the peasantry in Michael Cacoyannis' Electra (1962)", en BAKOGIANnI, A. (ed.), Dialogues with the past 1. Classical Reception, Theory and Practice, Institute of Classical Studies, London, pp. 207-223.

De EspañA, R. (2017): De héroes y dioses. 50 películas sobre la antigüedad, Editorial UOC, Barcelona.

De Martino, F. (2009): «La representación de la violencia trágica en el cine», en De MarTino, F. MORENILla, C. (eds.), Legitimación e institucionalización política de la violencia. Teatro y sociedad en la Antigüedad Clásica, Levante, Bari, pp. 375-386. 
García Romero, F. (1998): «Adaptaciones cinematográficas de la tragedia griega: puesta en escena antigua y moderna», en García Novo, E. - Rodríguez Alfageme, I. (eds.), Dramaturgia y puesta en escena en el teatro griego, Ediciones Clásicas, Madrid, pp. 193-203.

Karalis, V. (2016): Realism in Greek Cinema, I.B. Tauris, London-New York.

MacKinnon, K. (1986): Greek Tragedy into Film, Croom Helm, London.

McDonald, M. (1983): Euripides in cinema: The heart made visible, Centrum Philadelphia, Philadelphia.

McDonald, M. - Winkler, M. M. (2001): «Michael Cacoyannis and Irene Papas on Greek Tragedy», en WinkLer, M. M. (ed.), Classical Myth and Culture in the Cinema, Oxford University Press, New York, pp. 72-89.

Michelakis, P. (2013): Greek Tragedy on Screen, Oxford University Press, Oxford.

Mitiloudis, K. (2011): The Electra Myth in Euripides and Cacoyannis, Thesis, University of Johannesburg.

MoschovaKIs, A. (1995): «Mijalis Kakoyannis: Apo tin izografía stin tragodía», en KolOniAS, B. (ed.), Mijalis Kakoyannis. 36 Thessaloniki Film Festival, Kastaniotis, Athens, pp. 17-45.

Nikoloutsos, K. P. (2013): Ancient Greek Women in Film, Oxford University Press, Oxford.

SiafKOS, CH. (2009): Mijalis Kakoyannis. Se proto plano, Psichogios, Athens.

VAlverde García, A. (2012): «Michael Cacoyannis: la sabiduría de la simplicidad», en SALVAdor Ventura, F. (ed.), Cine y autor, Intramar Ediciones, Santa Cruz de Tenerife, pp. 155-168.

- (2015): «Una tragedia griega contra los abusos de poder: Las troyanas (1971) de Michael Cacoyannis», en Lapeña Marchena, O. - Pérez Murillo, M. D. (eds.), El poder a través de la representación filmica, Université Paris-Sud, Paris, pp. 325-341.

WILlIS, A. T. (2005): Euripides' Trojan Women: A 20th Century War play in performance, Thesis, University of Oxford.

WINKLER, M. M. (2017): Classical Literature on Screen: Affinities of Imagination, Cambridge University Press, New York. 